\title{
IS SUBCLINICAL HYPOTHYROIDISM IN PATIENTS WITH POLYCYSTIC OVARY SYNDROME ASSOCIATED WITH BMI?
}

\author{
H.Y. Yasar ${ }^{1, *}$, O. Topaloglu², M. Demirpence ${ }^{1}$, B.O. Ceyhan ${ }^{3}$, F. Guclu ${ }^{1}$ \\ Tepecik Research and Training Hospital, ${ }^{1}$ Dept. of Endocrinology, ${ }^{2}$ Dept. of Internal Medicine, Izmir, ${ }^{3}$ Medline \\ Hospital, Dept. of Endocrinology, Aydin, Turkey
}

\begin{abstract}
Objective. To investigate the impact of body weight on the subclinical hypothyroidism observed in patients with PCOS.

Methods. The study included 95 normal weight (Group-1) and 122 overweight or obese women (Group-2) with PCOS. The control group consisted of age and BMI matched healthy individuals and grouped as normal weight (n: 66, Group-3) and overweight or obese (n: 65, Group-4. Women with chronic disease such as overt thyroid dysfunction, late-onset adrenal hyperplasia, and diabetes were excluded from the study. Plasma glucose and lipid profile, thyroid hormones, insulin, FSH, LH, total testosterone, estradiol, progesterone and DHEA-S were measured.
\end{abstract}

Results. While fasting glucose was similar, insulin and HOMA-IR were higher in Group-2 and Group-4 (p: 0.001). The groups were similar with respect to FSH, Estradiol, prolactine, DHEAS. While total testosterone and LH levels were higher (ptestosterone: 0,009), progesterone was lower in both PCOS groups (pprogesterone: 0.041). Free T3, free T4, thyroid antibodies were similar between the groups, but the prevalence of subclinical hypothyroidism was greater in Group-2 and -4 than in Group-1 and -3 (p: 0.044). TSH was only correlated with BMI (r: 0.122, p: $0.02)$.

Conclusion. The increased prevalence of subclinical hypothyroidism in women with PCOS might be the result of increased BMI.

Key words: polycystic ovary syndrome, subclinical hypothyroidism, autoimmune thyroiditis, obesity.

\section{INTRODUCTION}

Polycystic ovary syndrome (PCOS) is a common endocrine metabolic disorder that affects $5-10 \%$ of women of reproductive age (1-3). This syndrome is characterized by hyperandrogenism (clinical and/or biochemical), oligo-amenorrhea and polycystic ovaries at pelvic ultrasound. For diagnosis, two out of these three criteria are sufficient (4). PCOS is associated with general or abdominal obesity, insulin resistance and dyslipidemia, higher prevalence of impaired glucose tolerance, type 2 diabetes and metabolic syndrome (4-6). Women with PCOS are at risk for chronic unovulation, infertility and early pregnancy loss. In addition many are obese and the number of obese individuals among patients with PCOS are increasing $(7,8)$.

Hypothyroidism has also been shown to cause metabolic abnormalities, such as decrease in glucose disposal, increase in the level of sex-hormone-binding globulin, weight gain, hyperlipidemia. It also affects gonadal function and fertility leading to PCOS-like disorder $(9,10)$. The association between PCOS and overt hypothyroidism is well-studied and there are various reports about the prevalence of subclinical hypothyroidism in patients with PCOS $(1,4,7,9,11$ 15). In addition to PCOS, obesity itself has also been shown to be associated with subclinical hypothyroidism (16-22). In order to evaluate the impact of obesity on subclinical hypothyroidism, we aimed to investigate and compare the prevalence of subclinical hypothyroidism in both normal weight and overweight or obese patients with PCOS.

\section{MATERIALS AND METHODS}

\section{Patients study design}

The study was a single-center, prospective, casecontrol study that included 95 normal weight (group-1) and 122 overweight or obese women (group-2) with a diagnosis of PCOS defined in accordance with the Rotterdam criteria (23). The control group consisted of age and BMI matched healthy females and included 66 normal weight (group-3) and 65 overweight or obese (group-4) controls. The study was carried out between January 2013 and February 2015 at the Department

*Correspondence to: Hamiyet Y1lmaz Yasar MD, Tepecik Research and Training Hospital, Department of Endocrinology, Izmir, Turkey, E-mail: drhamiyetyilmaz@yahoo.com 
of Endocrinology in Tepecik Research and Training Hospital. Women with chronic diseases such as overt hypothyroidism or hyperthyroidism, kidney and liver failure, hyperprolactinemia, late-onset adrenal hyperplasia, diabetes, hypertension, Cushing syndrome and women taking thyroid hormone or anti-thyroid medication were excluded from the study. Also women who had been receiving hormonal therapy including oral contraceptive pills or steroids (glucocorticoids) within six months were excluded. The study was approved by the medical ethics committee of the Tepecik Research and Training Hospital and all participants provided written informed consent.

Body mass index (BMI) and waist circumference were measured in all study subjects. BMI was calculated by the ratio between weight and height squared in $\mathrm{kg} /$ $\mathrm{m}^{2}$. Waist circumference was measured on bare skin between the tenth rib and the iliac crest in centimeters. Hirsutism was evaluated based on the Ferriman-Gallwey scoring index over nine body areas (24).

After an overnight fast of 12 hours, venous blood was collected from the antecubital vein for the evaluation of following biochemical parameters: plasma glucose and lipid profile (total cholesterol, HDL cholesterol, LDL cholesterol and triglycerides) and hormonal evaluation including: estradiol, progesterone, total testosterone, prolactine, insulin, DHEA-S, FSH, LH, free T3, free T4, TSH, anti-thyroperoxidase (anti-TPO) antibody, antithyroglobulin (anti-Tg) antibody. The blood samples were obtained during the $3^{\text {rd }}$ to $9^{\text {th }}$ days of menstrual cycle or 60 days after the last menstrual period. Thyroid ultrasonography was perfomed in all study subjects.

\section{Laboratory Assessments}

Glucose concentrations were measured by a hexokinase method with the Olympus AU-2700 analyzer. Triglycerides, total cholesterol and HDLcholesterol were measured by an enzymatic method with Olympus AU-2700 analyzer using reagents from Olympus Diagnostics (Gmbh, Hamburg, Germany). LDL-cholesterol was calculated by the Friedewald's equation method. Fasting insulin, prolactine, estradiol, progesterone, total testosterone, DHEA-S, FSH, LH, free T3, free T4, TSH, anti-TPO, anti-Tg levels were measured by chemiluminescent method by Immulite 2000 otoanalyzer (Immulite XPi, Siemens, Germany). Homeostasis model assessment (HOMA) was used as a measure of insulin sensitivity using the equation= fasting insulin $(\mathrm{mU} / \mathrm{L}) \mathrm{X}$ glucose $(\mathrm{mmol} / \mathrm{L}) / 22.5$. Insulin resistance is defined as having a HOMA value $>2.7$ as suggested by Matthews et al. (25).
Ultrasonography of the thyroid gland: The thyroid was evaluated by using a $7.5 \mathrm{mHz}$ linear transducer (Logiq 5 Pro, GE Medical Systems, WI, USA). Thyroid volume was calculated by the elliptical shape volume formula ( $0.479 \mathrm{X}$ length $\mathrm{X}$ width $\mathrm{X}$ height $)$ for each lobe (26). Nodule volume was calculated using the formula for the volume of a prolate elipse $(0.523$ $\mathrm{X}$ length $\mathrm{X}$ width $\mathrm{X}$ diameter). All ultrasonographic evaluations were performed by the same radiologist.

\section{Statistical Analysis}

Results are expressed as means \pm SD. The Chi-Square test was used for the comparison of nonparametric independent variables in two-group or multiple group analysis. Kruskal Wallis test was used for multiple group comparisons of normally distributed parametric variables and Mann-Whitney $U$ test was used for two-group comparisons. For subgroup analysis with Bonferroni correction Mann-Whitney U test was used. Pearson correlation analysis was used to evaluate correlation between normally distributed parameters and Spearsman rho test was used if not normally distributed. $\mathrm{P}<0.05$ was considered statistically significant. Statistical analysis was performed with SPSS 15.0 statistical software.

\section{RESULTS}

The mean age of women was $23.98 \pm 6.11$ in group-1, $25.65 \pm 5.89$ in group-2, $25.15 \pm 7.03$ in group- 3 and $27.10 \pm 7.53$ in group- 4 and it was similar in all four groups (Table 1). As expected, BMI and waist circumference was significantly different between four groups, but they were similar between group-1 (normal weight PCOS) and group-3 (normal weight control) (pBMI: 0.093, pwaist circumference: 0.942), and group-2 (overweight or obese PCOS) and group-4 (overweight or obese control) (pBMI: 0.678, pwaist circumference: 0.593). In the evaluation of hirsutism, Ferriman-Gallwey index was higher in both PCOS groups with respect to controls (p: 0.001).

While mean fasting glucose was similar between all four groups, insulin and HOMA-IR values were significantly different (pinsulin: 0.001, pHOMA: 0.001) (Table 2). However, in two group comparisons they were similar in group-1 and group-3 (pinsulin: 0.170, pHOMA: 0.169), and group-2 and group-4 (pinsulin: 0.090, pHOMA: 0.495). Also LDL- and HDL-cholesterol and triglyceride levels were different between all groups. LDL-cholesterol was significantly lower in group-3, but it was similar in group-1, group-2 
Table 1. Clinical characteristics of the study population

\begin{tabular}{lllll}
\hline & $\begin{array}{l}\text { Goup-1 } \\
\text { (Normal weight PCOS) }\end{array}$ & $\begin{array}{l}\text { Group-2 } \\
\text { (overweight or obese PCOS) }\end{array}$ & $\begin{array}{l}\text { Group-3 } \\
\text { (Normal weight control) }\end{array}$ & $\begin{array}{l}\text { Group-4 } \\
\text { (overweight or obese } \\
\text { control) }\end{array}$ \\
\hline Age & $23.98 \pm 6.11$ & $25.65 \pm 5.89$ & $25.15 \pm 7.03$ & $27.10 \pm 7.53$ \\
BMI $\left(\mathrm{kg} / \mathrm{m}^{2}\right)$ & $21.96 \pm 1.7$ & $33.51 \pm 5.16$ & $21.47 \pm 1.97$ & $32.31 \pm 5.31$ \\
Waist circumference $(\mathrm{cm})$ & $71.69 \pm 7.36$ & $99.33 \pm 12.81$ & $72.51 \pm 7.09$ & $95.14 \pm 11.83$ \\
Ferriman-Gallway index & $9.09 \pm 3.04$ & $8.95 \pm 2.94$ & $5.83 \pm 2.75$ & 0.001 \\
\hline
\end{tabular}

Table 2. Laboratory parameters of the study population

\begin{tabular}{lllll}
\hline & $\begin{array}{l}\text { Goup-1 } \\
\text { (Normal weight PCOS) }\end{array}$ & $\begin{array}{l}\text { Group-2 } \\
\text { (overweight or obese PCOS) }\end{array}$ & $\begin{array}{l}\text { Group-3 } \\
\text { (Normal weight } \\
\text { control) }\end{array}$ & $\begin{array}{l}\text { Group-4 } \\
\text { (overweight or obese } \\
\text { control) }\end{array}$ \\
\hline Fasting glucose(mg/dL) & $86.92 \pm 8.99$ & $89.93 \pm 15.24$ & $84.65 \pm 9.91$ & $90.27 \pm 10.17$ \\
Insulin $(\mu \mathrm{P} / \mathrm{mL})$ & $11.81 \pm 9.28$ & $19.56 \pm 18.25$ & $9.86 \pm 8.15$ & $17.09 \pm 39.55$ \\
HOMA & $2.46 \pm 1.86$ & $4.53 \pm 5.06$ & $2.07 \pm 1.66$ & $4.06 \pm 6.96$ \\
LDL-cholesterol (mg/dL) & $111.97 \pm 31.95$ & $115.33 \pm 30.36$ & $99.65 \pm 26.73$ & $112.34 \pm 30.84$ \\
HDL-cholesterol $(\mathrm{mg} / \mathrm{dL})$ & $49.62 \pm 13.42$ & $43.41 \pm 9.13$ & $49.58 \pm 10.53$ & $44.06 \pm 8.42$ \\
Total cholesterol $(\mathrm{mg} / \mathrm{dL})$ & $183.38 \pm 37.82$ & $185.98 \pm 37.21$ & $165.49 \pm 31.31$ & $180.74 \pm 37.26$ \\
Triglyceride $(\mathrm{mg} / \mathrm{dL})$ & $114.25 \pm 68.41$ & $136.22 \pm 83.49$ & $89.21 \pm 46.98$ & $121.65 \pm 80.17$ \\
FSH $(\mathrm{mIU} / \mathrm{mL})$ & $5.61 \pm 2.51$ & $5.89 \pm 2.95$ & $5.86 \pm 3.95$ & $5.62 \pm 4.86$ \\
LH $(\mathrm{mIU} / \mathrm{mL})$ & $9.61 \pm 8.99$ & $7.42 \pm 5.04$ & $6.43 \pm 5.81$ & $6.26 \pm 6.16$ \\
Estradiol $(\mathrm{pg} / \mathrm{mL})$ & $75.12 \pm 64.03$ & $72.76 \pm 56.66$ & $74.31 \pm 57.75$ & $95.72 \pm 76.94$ \\
Total testosterone $(\mathrm{ng} / \mathrm{dL})$ & $40.28 \pm 23.33$ & $42.09 \pm 23.81$ & $32.01 \pm 14.41$ & $33.99 \pm 21.66$ \\
Progesterone $(\mathrm{ng} / \mathrm{mL})$ & $1.35 \pm 1.17$ & $1.24 \pm 1.01$ & $2.36 \pm 1.18$ & $2.60 \pm 1.52$ \\
Prolactine $(\mathrm{ng} / \mathrm{mL})$ & $13.79 \pm 14.72$ & $12.24 \pm 12.04$ & $12.43 \pm 9.44$ & $13.21 \pm 15.93$ \\
DHEA-S $(\mu \mathrm{g} / \mathrm{dL})$ & $276.18 \pm 139.56$ & $254.65 \pm 112.11$ & $265.08 \pm 104.51$ & $235.41 \pm 118.92$ \\
fT3 $(\mathrm{pg} / \mathrm{mL})$ & $3.85 \pm 0.95$ & $4.01 \pm 0.73$ & $4.03 \pm 1.16$ & $4.03 \pm 1.16$ \\
fT4 $(\mathrm{ng} / \mathrm{mL})$ & $1.04 \pm 0.17$ & $1.05 \pm 0.16$ & $1.07 \pm 0.17$ & $1.02 \pm 0.17$ \\
TSH $(\mathrm{uIU} / \mathrm{mL})$ & $2.25 \pm 1.63$ & $3.51 \pm 3.18$ & $2.01 \pm 1.41$ & $4.55 \pm 4.26$ \\
Anti-TPO $(\mathrm{IU} / \mathrm{mL})$ & $96.64 \pm 85.87$ & $120.56 \pm 65.54$ & $80.92 \pm 58.28$ & $75.84 \pm 64.28$ \\
Anti-thyroglobulin $(\mathrm{IU} / \mathrm{mL})$ & $107.12 \pm 51.92$ & $77.56 \pm 60.53$ & $65.73 \pm 48.19$ & $85.93 \pm 57.32$ \\
\hline
\end{tabular}

Table 3. The Prevalence of Autoimmume thyroiditis and subclinical hypothyroidism in the study population

\begin{tabular}{lllll}
\hline & $\begin{array}{l}\text { Goup-1 } \\
\text { (Normal weight PCOS) }\end{array}$ & $\begin{array}{l}\text { Group-2 } \\
\text { (overweight or obese } \\
\text { PCOS) }\end{array}$ & $\begin{array}{l}\text { Group-3 } \\
\text { (Normal weight control) }\end{array}$ & $\begin{array}{l}\text { Group-4 } \\
\text { (overweight or obese control) }\end{array}$ \\
\hline $\begin{array}{l}\text { Autoimmune } \\
\text { thyroiditis (\%) }\end{array}$ & 17.9 & 24.3 & 18.5 & 16.9 \\
$\begin{array}{l}\text { Subclinical } \\
\text { hypothyroidism (\%) }\end{array}$ & 13.05 & 27.08 & 12.86 & 30.95 \\
\hline
\end{tabular}

and group-4 ( $\mathrm{p}>0.05$ in two group comparisons). HDLcholesterol was lower in group-2 and group-4, with respect to group-1 and group-3. Triglyceride level was significantly higher in group-2, with respect to the rest of the groups. All the groups were similar with respect to serum FSH, Estradiol, prolactine, DHEAS levels. Since DHEAS is an abundant steroid that is mainly from adrenal source, its levels may not be elevated in patients with PCOS (2). While total testosterone and LH levels were higher in both PCOS groups, than in control groups (ptestosterone: 0.009 , pLH: 0.002 ), progesterone levels were lower in both PCOS groups (pprogesterone: 0.041).

When thyroid function tests were considered, we observed that serum free $\mathrm{T} 3$ and free $\mathrm{T} 4$ were similar in all groups, but TSH value was significantly higher in group-2 and group-4, than in group-1 and 3 (p: 0.002). It was not different between group- 2 and group-4 (p: 0.260 ) and group -1 and 3 (p: 0.322).

In the evaluation of anti-thyroperoxidase antibody, anti-thyroglobulin antibody and thyroid gland volume, no significant differences were observed between the groups. The prevalence of autoimmume thyroiditis was not different between all groups (p: 0.252) (Table 3). In contrast to autoimmune thyroiditis, subclinical hypothyroidism prevalence was different between four groups (p: 0.044). In two group comparisons, while the prevalence of subclinical hypothyroidism 
was similar between normal weight PCOS and normal weight control groups (p: 0.362) and overweight or obese PCOS and overweight or obese control groups (p: 0.246), it was significantly different between normal weight and overweight or obese PCOS groups (p: 0.032) and the two control groups (p: 0.015). We also evaluated the women in both PCOS groups and control groups based on the existence of subclinical hypothyroidism. In control group, subclinical hypothyroid patients had higher BMI than euthyroid ones (p: 0.01). In PCOS group, subclinical hypothyroid patients had higher BMI, HOMA-IR, total and LDL-cholesterol values than euthyroid patients (pBMI: 0.03, pHOMA: 0.004, pLDL: 0.008, ptotal cholesterol: 0.003).

When correlation analysis was carried out, TSH was only correlated with BMI (p: 0.02) and no correlation between free T3, free T4, TSH and the other studied parameters. Multiple regression analysis revealed that BMI was only the independent predictor of TSH, after controlling for the effect of insulin resistance (HOMA) (p: 0.025).

\section{DISCUSSION}

The prevalence of subclinical hypothyroidism in women with PCOS and the association of subclinical hypothyroidism and insulin resistance and lipid parameters in patients with PCOS has already been studied (1, 4,11-13). However, the present study is the first study that evaluated subclinical hypothyroidism both in normal weight and overweight or obese PCOS patients and age and BMI-matched control groups.

Subclinical hypothyroidism is common in women of reproductive age, with a prevalence ranging from $4-9 \%$ in this population $(1,4,7)$. There are various studies which investigated subclinical hypothyroidism in patients with PCOS $(1,4,11-13)$. Benetti-Pinto et al. observed that $11.3 \%$ of the women with PCOS had subclinical hypothyroidism (1). While this prevalence was found to be $11.5 \%$ by Garelli, it was reported to be $16.9 \%$ by Novais Jde $(4,13)$. In our study we showed that $13.05 \%$ of normal-weight PCOS patients and 27.08 $\%$ overweight or obese PCOS patients had subclinical hypothyroidism. Due to the higher prevalence of subclinical hypothyroidism in PCOS patients with respect to controls, it was suggested that a relationship existed between thyroid dysfunction and PCOS. However, it was not clear whether subclinical hypothyroidism induced an increase in the prevalence of PCOS or whether subclinical hypothyroidism was a consequence of PCOS (1). Studies in rats showed that induction of hypothyroidism resulted in hyperandrogenemia and ovarian follicular cyst formation which were cardinal signs of PCOS (27). Severe long-standing hypothyroidism in women also lead to elevated androgen levels and ovarian cyst formation. Decrease in ovarian volume, resolution of ovarian cysts and reversal of the polycystic ovary syndrome-like appearance, together with improvement in serum hormone levels, occurred after euthyroidism was achieved (28). On the other hand, studies with metformin in women with PCOS and hypothyroidism have shown a reduction in serum TSH levels, indicating that treating insulin resistance may improve subclinical hypothyroidism $(29,30)$.

Increased prevalence of subclinical hypothyroidism in patients with PCOS might also be explained by increased body weight in these patients. Thyroid function was found to be related to weight status, as reported by Reinehr et al., with increased TSH levels in obese women (31) and the increase in TSH normalized after weight loss (32). Likewise, Solanki et al. observed that as BMI increased, TSH levels were increased (19) and this observation was demonstrated by other studies $(17,18,21,22,33,34)$. In accordance with these reports, in our study we observed increased prevalence of subclinical hypothyroidism both in overweight or obese PCOS group (27.08\%) and control group (30.95\%), with respect to normal weight PCOS and control groups.

Although aforementioned studies and our study suggested an association between serum TSH and high BMI, they did not clarify whether the high-normal serum TSH was the consequence or the cause of obesity (17). As a matter of fact, the causes responsible for the increased serum levels of TSH in obese patients are still debated. The observation that TSH levels normalized after weight loss, resulting either from hypocaloric diet or bariatric surgery $(17,35)$, suggested that in obese patients the increased TSH was an adaptive response of the hypothalamus-pituitary-thyroid axis to weight gain. Leptin, an adipocyte-derived hormone, that inhibits of food intake and stimulates both energy expenditure and locomotor activity, was proposed to be involved in the adaptive response of the hypothalamus-pituitarythyroid axis to weight gain. Since leptin receptors were found on pituitary and TRH-secreting neurons of the paraventricular nucleus, besides the arcuate nucleus of hypothalamus, increased leptin levels and leptin resistance in obesity, might directly stimulate the hypothalamus-pituitary-thyroid axis and cause increased TSH levels (17). In contrast to findings which supported the hypothesis that obesity was the cause of increased $\mathrm{TSH}$, a study in mice showed that TSH increased 
triglyceride accumulation, via TSH receptor in which GPAT3 activation was induced by AMPK/PPAR- $\gamma$ signaling pathway, and caused obesity. Also, ablation of TSH receptor in mice caused resistance to high-fat diet induced obesity (16).

The women with PCOS who have subclinical hypothyroidism, were found to have higher LDLcholesterol levels than euthyroid women with PCOS and a positive correlation was reported between serum TSH and LDL-cholesterol levels (1). However, in other two studies which include patients with PCOS, lipid profile - except serum TG levels - was similar between subclinical hypothyroid and euthyroid women. Serum TG was higher in subclinical hypothyroid group (9, 36). Mueller et al. did not demonstrate any changes in levels of total cholesterol, TG and LDL among euthyroid PCOS subjects who were categorized on the basis of a TSH cut-off value of 2 IU/L (7). In our study, we observed higher total and LDL-cholesterol values in subclinical hypothyroid PCOS patients than euthyroid PCOS patients (pldl: 0.008, ptotal: 0.003). Whether $\mathrm{SCH}$ alters the phenotypic expression of people with PCOS or whether SCH has effect on insulin resistance in these people is not clear (9). There was no difference in HOMA-IR values between women with PCOS and normal thyroid function and those with PCOS and SCH $(1,9,36)$. Mueller et al. found that women with TSH $\geq 2$ IU/L had elevated insulin resistance compared with women who had $\mathrm{TSH}<2$ IU/L. The group with $\mathrm{TSH} \geq 2$ IU/L had a higher BMI, but insulin resistance persisted even after correction of factors like BMI and age (7). In our study, we demonstrated higher HOMA-IR values in subclinical hypothyroid women with PCOS compared to women with euthyroid PCOS (phoma: 0.004). However, TSH levels were only positively correlated with BMI ( $\mathrm{p}$ : 0.02 ) and we observed no correlation between free T3, free T4, TSH and the other studied parameters.

The prevalence of autoimmune thyroiditis was reported to be higher in patients with $\operatorname{PCOS}(4,11,12)$. Janssen et al. observed a threefold higher prevalence of autoimmune thyroiditis in young PCOS patients (26.9\%) compared with age-matched controls $(8.3 \%)$ (12). Garelli et al. showed that $27 \%$ of PCOS patients and $8 \%$ of controls had autoimmune thyroiditis (4). In our study, we did not observe any difference between both PCOS and control groups. Autoimmume thyroiditis (AIT) prevalence was $20.5 \%$ in group- $1,24.3 \%$ in group-2, $18.5 \%$ in group- 3 and $16.9 \%$ in group- 4 . The prevalence of AIT in both PCOS groups were similar with previous reports, but the prevalence of AIT in both control groups were higher than in previous reports.
This can be explained by that thyroid autoimmunity was increased after iodine supplementation (11). Iodine deficiency was prevalent in Turkey before 1994 and after that due to the mandatory salt iodization programme of the ministry of health, the prevalence of iodide deficiency was decreased. As suggested by Kachuei et al. and Khalili et al., the incidence of thyroid autoimmunity might increase after iodine supplementation (11). The reason for high incidence of AIT in PCOS is not welldefined. To date, a common genetic background has not been found. However, other autoimmune disorders were reported to be more common in PCOS and anti-nuclear antibodies (ANA) and smooth-muscle antibodies (SMA) were found in $40.7 \%$ of PCOS patients and $14.8 \%$ of controls $(12,37)$. Another hypothesis for the increase in prevalence of AIT in PCOS is the imbalance of normal to high estrogens and low progesterone levels, the so-called 'unopposed estrogens' (12). Estrogens were known to increase interleukin- 4 expression in TH2 cells, IL-1 in monocytes, IL-6 in T-cells and interferon gamma in TH1 cells (38) and the immune stimulatory activity of estrogens was thought to be counteracted by progesterone. As patients with PCOS have no or nearly no progesterone because of unovulatory cycles, the immune stimulatory activity of estrogens in these patients should be overstimulated, that might propagate autoimmune disease (12). This hypothesis, however, was not consistent with the reported higher prevalence of hypothyroidism during the menopause (4). In previous studies and in our study, no correlation was observed between thyroid autoimmunity and hormonal parameters $(4,12)$.

In conclusion, the present study demonstrated that the increased prevalence of subclinical hypothyroidism in women with PCOS might be the result of increased BMI. Therefore, routine screening of thyroid hormones in normal weight women with PCOS may not be necessary unless fertility is desired. However, prospective, controlled trials with long term follow-up including both normal weight and obese PCOS patients are needed to clarify the impact of BMI on TSH.

\section{Conflict of interest}

The authors declare that they have no conflict of interest concerning this article.

\section{References}

1. Benetti-Pinto CL, Piccolo VR, Garmes HM, Juliato CR. Subclinical hypothyroidism in young women with polycystic ovary syndrome: an analysis of clinical, hormonal, and metabolic parameters. Fertil Steril 2013; 99(2):588-592.

2. Azziz R, Carmina E, Dewailly D, Diamanti-Kandarakis E, 


\section{H.Y. Yasar et al.}

Escobar-Morreale HF, Futterweit W, Janssen OE, Legro RS, Norman RJ, Taylor AE, Witchel SF; Androgen Excess Society. Positions statement: criteria for defining polycystic ovary syndrome as a predominantly hyperandrogenic syndrome: an Androgen Excess Society guideline. J Clin Endocrinol Metab 2006; 91(11):4237-4245. 3. Adams J, Polson DW, Franks S. Prevalence of polycystic ovaries in women with anovulation and idiopathic hirsutism. Br Med J (Clin Res Ed) 1986; 293(6543):355-359.

4. Garelli S, Masiero S, Plebani M, Chen S, Furmaniak J, Armanini D, Betterle C. High prevalence of chronic thyroiditis in patients with polycystic ovary syndrome. Eur J Obstet Gynecol Reprod Biol. 2013;169(2):248-251.

5. Moran LJ, Misso ML, Wild RA, Norman RJ. Impaired glucose tolerance, type 2 diabetes and metabolic syndrome in polycystic ovary syndrome: a systematic review and meta-analysis.Hum Reprod Update 2010;16(4):347-363.

6. Amato MC, Verghi M, Galluzzo A, Giordano C. The oligomenorrhoic phenotypes of polycystic ovary syndrome are characterized by a high visceral adiposity index: a likely condition of cardiometabolic risk. Hum Reprod 2011; 26(6):1486-1494.

7. Mueller A, Schöfl C, Dittrich R, Cupisti S, Oppelt PG, Schild RL, Beckmann MW, Häberle L. Thyroid-stimulating hormone is associated with insulin resistance independently of body mass index and age in women with polycystic ovary syndrome. Hum Reprod 2009; 24(11):2924-2930.

8. Yildiz BO, Knochenhauer ES, Azziz R. Impact of obesity on the risk for polycystic ovary syndrome.J Clin Endocrinol Metab 2008; 93(1):162-168.

9. Ganie MA, Laway BA, Wani TA, Zargar MA, Nisar S, Ahamed F, Khurana ML, Ahmed S. Association of subclinical hypothyroidism and phenotype, insulin resistance, and lipid parameters in young women with polycystic ovary syndrome. Fertil Steril 2011; 95(6):2039-2043.

10. Setian NS. Hypothyroidism in children: diagnosis and treatment. J Pediatr (Rio J) 2007; 83(5 Suppl): S209-216.

11. Kachuei M, Jafari F, Kachuei A, Keshteli AH. Prevalence of autoimmune thyroiditis in patients with polycystic ovary syndrome. Arch Gynecol Obstet 2012;285(3):853-856.

12. Janssen OE, Mehlmauer N, Hahn S, Offner AH, Gartner R. High prevalence of autoimmune thyroiditis in patients with polycystic ovary syndrome. Eur J Endocrinol. 2004;150(3):363-369.

13. Novais Jde S, Benetti-Pinto CL, Garmes HM, Jales RM, Juliato $\mathrm{CR}$. Polycystic ovary syndrome and chronic autoimmune thyroiditis. Gynecol Endocrinol 2015; 31(1):48-51.

14. Huang R, Zheng J, Li S, Tao T, Liu W. Subclinical hypothyroidism in patients with polycystic ovary syndrome: distribution and its association with lipid profiles. Eur J Obstet Gynecol Reprod Biol 2014; 177:52-56.

15. Morgante G, Musacchio MC, Orvieto R, Massaro MG, De Leo V. Alterations in thyroid function among the different polycystic ovary syndrome phenotypes. Gynecol Endocrinol 2013; 29(11):967-969.

16. Ma S, Jing F, Xu C, Zhou L, Song Y, Yu C, Jiang D, Gao L, Li Y, Guan Q, Zhao J. Thyrotropin and obesity: increased adipose triglyceride content through glycerol-3-phosphate acyltransferase 3. Sci Rep. 2015 Jan 6;5:7633.

17. Santini F, Marzullo P, Rotondi M, Ceccarini G, Pagano L, Ippolito S, Chiovato L, Biondi B. Mechanisms in endocrinology: the crosstalk between thyroid gland and adipose tissue: signal integration in health and disease. Eur J Endocrinol 2014;171(4):137-152.

18. Mamtani M, Kulkarni H, Dyer TD, Almasy L, Mahaney MC, Duggirala R, Comuzzie AG, Samollow PB, Blangero J, Curran JE. Increased waist circumference is independently associated with hypothyroidism in Mexican Americans: replicative evidence from two large, population-based studies. BMC Endocr Disord 2014; 14(46):1-13.

19. Solanki A, Bansal S, Jindal S, Saxena V, Shukla US. Relationship of serum thyroid stimulating hormone with body mass index in healthy adults. Indian J Endocrinol Metab 2013; 17(Suppl 1): 167-169.
20. Lee YK, Kim JE, Oh HJ, Park KS, Kim SK, Park SW, Kim MJ, Cho YW. Serum TSH level in healthy Koreans and the association of TSH with serum lipid concentration and metabolic syndrome. Korean J Intern Med 2011; 26(4):432-439.

21. Lai Y, Wang J, Jiang F, Wang B, Chen Y, Li M, Liu H, Li C, Xue H, Li N, Yu J, Shi L, Bai X, Hou X, Zhu L, Lu L, Wang S, Xing Q, Teng X, Teng W, Shan Z. The relationship between serum thyrotropin and components of metabolic syndrome.Endocr J 2011; 58(1):23-30.

22. Rotondi M, Leporati P, La Manna A, Pirali B, Mondello T, Fonte $\mathrm{R}$, Magri F, Chiovato L. Raised serum TSH levels in patients with morbid obesity: is it enough to diagnose subclinical hypothyroidism? Eur J Endocrinol 2009; 160(3):403-408.

23. The Rotterdam ESHRE/ASRM-sponsored PCOS consensus workshop group Revised 2003 consensus on diagnostic criteria and long-term health risks related to polycystic ovary syndrome (PCOS). Hum. Reprod 2004; 19 (1): 41-47.

24. Ferriman D, Gallwey JD. Clinical assessment of body hair growth in women. J Clin Endocrinol Metab 1961; 21:1440-1447.

25. Matthews DR, Hosker JP, Rudenski AS, Naylor BA, Treacher DF, Turner RC. Homeostasis model assessment: insulin resistance and $\beta$-cell function from fasting plasma glucose and insulin concentrations in man. Diabetologia 1985;28(7):412-419.

26. Brunn J, Block U, Ruf G, Bos I, Kunze WP, Scriba PC. Volumetric analysis of thyroid lobes by real-time ultrasound. Dtsch Med Wochenschr 1981;106(41):1338-1340.

27. Bagavandoss P, England B, Asirvatham A, Bruot BC. Transient induction of polycystic ovary-like syndrome in immature hypothyroid rats. Proc Soc Exp Biol Med 1998 ;219(1):77-84.

28. Muderris II, Boztosun A, Oner G, Bayram F. Effect of thyroid hormone replacement therapy on ovarian volume and androgen hormones in patients with untreated primary hypothyroidism.Ann Saudi Med 2011;31(2):145-151.

29. Rotondi M, Cappelli C, Magri F, Botta R, Dionisio R, Iacobello C, De Cata P, Nappi RE, Castellano M, Chiovato L. Thyroidal effect of metformin treatment in patients with polycystic ovary syndrome. Clin Endocrinol 2011;75(3):378-381.

30. Morteza Taghavi S, Rokni H, Fatemi S. Metformin decreases thyrotropin in overweight women with polycystic ovarian syndrome and hypothyroidism.. Diab Vasc Dis Res. 2011; 8(1):47-48.

31. Reinehr T, Isa A, de Sousa G, Dieffenbach R, Andler W. Thyroid hormones and their relation to weight status. Horm Res 2008;70(1):51-57.

32. Reinehr T, de Sousa G, Andler W. Hyperthyrotropinemia in obese children is reversible after weight loss and is not related to lipids. J Clin Endocrinol Metab 2006; 91(8):3088-3091.

33. Sari R, Balci MK, Altunbas H \& Karayalcin U. The effect of body weight and weight loss on thyroid volume and function in obese women. Clinical Endocrinology 2003; 59(2): 258-262.

34. Taylor PN, Razvi S, Pearce SH, Dayan CM Clinical review: A review of the clinical consequences of variation in thyroid function within the reference range. J Clin Endocrinol Metab 2013; 98(9):3562-3571.

35. Kok P, Roelfsema F, Langendonk JG, Frolich M, Burggraaf J,Meinders AE \& Pijl H. High circulating thyrotropin levels in obese women are reduced after body weight loss induced by caloric restriction. Journal of Clinical Endocrinology and Metabolism 2005; 90(8):4659-4663.

36. Celik C, Abali R, Tasdemir N, Guzel S, Yuksel A, Aksu E, Yılmaz M. Is subclinical hypothyroidism contributing dyslipidemia and insulin resistance in women with polycystic ovary syndrome? Gynecol Endocrinol 2012;28(8):615-618.

37. Reimand K, Talja I, Metsküla K, Kadastik U, Matt K, Uibo R. Autoantibody studies of female patients with reproductive failure. J Reprod Immunol 2001; 51(2):167-176.

38. Angstwurm MW, Gärtner R, Ziegler-Heitbrock HW. Cyclic plasma IL-6 levels during normal menstrual cycle. Cytokine 1997; 9(5):370-374. 